\title{
Desenvolvimentismo e mercantilização da terra: transição e resistência das várzeas paraenses
}

\section{Developmentalism and land commodification: transition and resistance of the floodplains of Pará}

Ana Clándia Duarte Cardoso - Doutora em Arquitetura, pela Oxford Brookes University, UK. Professora da Universidade Federal do Pará (UFPA). E-mail: aclaudiacardoso@gmail.com

Raul da Silva Ventura Neto - Doutor em Desenvolvimento Econômico, pelo Instituto de Economia da Universidade Estadual de Campinas (UNICAMP). Professor da Faculdade de Arquitetura e Urbanismo da Universidade Federal do Pará (UFPA). E-mail: netoventuraraul@gmail.com

\section{Resumo}

O texto caracteriza o protagonismo histórico da biodiversidade amazônica e explica sua desvalorização em meio urbano e rural por ação do desenvolvimentismo e do avanço da mercantilização da terra rural na região. $\mathrm{O}$ texto apoia-se na análise documental, revisão de literatura e em cartografia sobre Belém e Mocajuba, cujos casos demonstram que os conflitos desse processo "invisibilizam" o habitante nativo, ampliam desigualdades e destroem sistemas de áreas verdes que poderiam contribuir para a correção dos equívocos do passado e para a promoção de justiça ambiental. Ressalta-se o protagonismo das cidades na difusão de uma nova estratégia de ocupação territorial para a região, para benefício da vida no planeta.

\section{Palavra-chave}

Várzea. Desenvolvimentismo. Políticas Públicas. Cidades Amazônicas. Mudanças Climáticas.

\begin{abstract}
The text characterizes the historical protagonism of the Amazonian biodiversity and explains its devaluation in urban and rural environment through the action of developmentalism and the advancement of rural land commercialization in the region. The article is based in documental analyses, literature review and cartography on Belém and Mocajuba, whose cases demonstrate that conflicts within this process "turn invisible" the native inhabitant, foster inequalities and destroy systems of green areas that could contribute to the correction of past mistakes and the promotion of environmental justice. It highlights the leading role of cities in the diffusion of a new strategy of territorial occupation for the region, for the benefit of life on the planet.
\end{abstract}

\section{Keywords}

Floodplain. Developmentalism. Public policy. Amazonian cities. Climate change. 


\section{INTRODUÇÃO}

Apesar do impacto da ação desenvolvimentista e das políticas públicas definidas em contextos metropolitanos na região Norte, tem havido uma longa resistência ao processo de dissolução da cultura de várzea amazônica. Se por um lado, ações e políticas não consideraram a produção de novas condições de trabalho e de vida a partir do trabalho velho (tradicional, não técnico, resultado do acúmulo de conhecimento há gerações) disponível na região, por outro, as transformações que elas desencadearam não foram capazes de possibilitar a incorporação de toda a população às condições de produção capitalistas, e particularmente industriais. Longe disso, a rapidez com que territórios urbanos e rurais foram reclamados como mercadoria promoveu um processo de desterritorialização e exclusão do camponês caboclo dentro e fora das cidades, transformando-o em pobre urbano, juntamente com os migrantes oriundos de outras regiões para a Amazônia.

A histórica distribuição de população em pequenas cidades e assentamentos nas calhas dos grandes rios, originados na sua maioria de antigos de sítios indígenas (VICENTINI, 2004), aproveitou a abundância da vida da várzea, garantida pelas cheias (STOLL, 2014). A conversão ao paradigma rodoviarista, à propriedade privada, ao aterro da várzea e à canalização de rios, em detrimento do modal fluvial, do uso da terra, e da várzea especialmente, como espaço comum, mudou o cenário dito tradicional e criou um simulacro de cidade industrial na Amazônia. Houve reprodução de tipologias, processos e políticas formulados em outros contextos, que negavam as águas e a sociobiodiversidade da região, e impuseram custos econômicos, ambientais, sociais e culturais que parecem estar acima da compreensão da sociedade local contemporânea.

Esta possibilidade existe porque, apesar da consolidação de novos campos disciplinares sobre mudanças climáticas e gestão do risco e desastres (IPCC, 2012), ainda não há debate teórico sobre o protagonismo da floresta e das águas para a permanência de práticas não capitalistas, ainda em curso dentro e fora das cidades, e sobre o potencial de solução para problemas contemporâneos que essas práticas oferecem. Em termos práticos, o desaparecimento de nascentes, a contaminação de águas superficiais e subterrâneas, os fenômenos de ilha de calor e inversão térmica, os desastres causados por inundações nos anos em que os moduladores climáticos intensificam as chuvas (La Niña), a subsidência, a desestruturação e erosão do solo, o assoreamento de rios, são processos direta ou indiretamente associados ao desmatamento na região, tanto quanto ao agravamento da pobreza do camponês-caboclo, transformado em pobre urbano (THERE..., 2011). 
Segundo Hecth, Pezzoli e Saatchi (2016), o Acordo Climático de Paris apontou que apesar de os países do Norte Global focarem a redução de emissões por meio de mudanças tecnológicas e menor consumo de energia, seria necessário incorporar a cobertura de vegetação como parte da solução do problema da redução de emissões de $\mathrm{CO}_{2}$; os autores destacam o protagonismo e a multifuncionalidade da floresta e da paisagem vegetada (benefícios para o ser humano, para a biosfera, para os sistemas hidrológicos, e para a regulação do microclima) para uma ação efetiva e de baixo custo nesta seara.

Nesta perspectiva, todos os sistemas verdes tornam-se relevantes, seja em áreas rurais ou em ambiente urbano (várzeas ou florestas urbanas e periurbanas, cinturões verdes cultiváveis etc.), assim como a possibilidade de produção de alimento e abastecimento próximo ao local de consumo, com baixa geração de emissões, como era a tradição na várzea amazônica.

Para Hecth, Pezzoli e Saatchi (2016, p. 2), a preservação do verde tem ideologia, ou seja, implica em regimes de conhecimento, controle institucional para o uso da terra, significado simbólico, sensibilidades, sinais econômicos e diversas relações de poder entre os níveis local, nacional e internacional; é uma questão de classe e de justiça ambiental. Nas décadas em que o desenvolvimentismo foi praticado de forma mais sistemática na Amazônia, as mudanças administrativas e institucionais permitiram a constituição de movimentos sociais, rurais e urbanos, que se tornaram protagonistas nos processos de resistência ao paradigma hegemônico e deixaram mais claras as diferenças de classe existentes na região, mas que carecem de visibilidade proporcional ao crescimento da pressão pela homogeneização do território desde o golpe de 2016.

A partir desse escopo, este texto oferece uma leitura de como as elites econômicas conseguiram desvalorizar o modo de vida tradicional e impor o desenvolvimentismo, como um paradigma de riqueza baseado no controle da terra e não mais na capacidade de manejo da biodiversidade, que depende da floresta viva, para indicar o impacto desse processo econômico sobre as circunstâncias socioambientais das cidades. A partir de revisão de literatura e da análise documental de planilhas oficiais e mapas históricos, procurou-se explicar como o foco mudou do controle de pessoas (os trabalhadores do extrativismo de coleta) que compreendiam a floresta e os rios, para o controle e loteamento da terra nua, e da discussão do território dos municípios de Belém, cuja sede é a cidade mais antiga da região, e de Mocajuba, inserido na região de várzea banhada pelo rio Tocantins, região onde o açaí (uma nova commodity) é endêmico.

As discussões apoiam-se em levantamentos de usos da terra relacionados ao manejo de vegetação nativa (realizados desde 2016 para Belém e entre 2018 e 2019 
para Mocajuba), em cartografias da institucionalização de unidades de conservação nos municípios estudados, e na relação entre infraestrutura logística, e de outras tipologias associadas ao desenvolvimentismo, com a expansão e adensamento da mancha urbana e a progressiva redução das massas vegetais dentro das cidades. Estes processos foram detectados a partir de viagens de campo e sobreposição de shapefiles às imagens de satélite disponíveis na plataforma Google Maps, e estão parcialmente representados nas figuras e quadros inseridos neste artigo.

\section{A VÁRZEA NA FORMAÇÃO SOCIOESPACIAL DA AMAZÔNIA}

O projeto original de colonização português, de transformar a Amazônia em uma economia colonial de plantation baseada na lógica do cultivo da terra pela mão de obra africana, foi frustrado pelas peculiaridades do bioma amazônico (COSTA, 2010a). A constatação de que havia produtos capazes de se tornarem "mercadorias prontas", que precisavam ser apenas colhidos, levou a uma guinada nas estratégias portuguesas de inserção da Amazônia na divisão internacional do trabalho da época. A região foi mantida como "almoxarifado", que viabilizava a exportação de produtos demandados na Europa, mas baseada no extrativismo de coleta ${ }^{1}$.

Esse mesmo autor apresenta dilemas e decisões tomadas na época (COSTA, 2012a). A constatação de que a mão de obra indígena era a única habilitada para desempenhar essa tarefa, apesar de nunca ter havido o reconhecimento devido de todas as obras e capacidades indígenas pré-colombianas pelo colonizador, gerou um impasse resolvido com medidas militares e religiosas - era preciso dominar o indígena. A partir das coalizões estabelecidas entre a Coroa Portuguesa e a Igreja Católica, foi feita a opção pela escravização do índio e sua catequização, para que ele se tornasse um "homem disciplinado para o louvor a Deus e para os trabalhos da terra, das águas e dos matos" (COSTA, 2010a, p. 178). A decisão de dominar por meio da catequização desencadeou um genocídio que forçou o indígena a se curvar à condição de força de trabalho dos agentes da Coroa. O extrativismo de coleta se estabelece moldando relações socioespaciais de produção altamente dependentes do conhecimento do nativo sobre floresta - a princípio, o índio, depois do caboclo resultante da miscigenação entre indivíduos portugueses e indígenas. Com o tempo, a evolução dessa relação de produção ampliou a

\footnotetext{
Segundo Costa (2010a), esse extrativismo poderia ser desenvolvido com a destruição de propriedades originais do ecossistema (extrativismo de aniquilamento) ou por meio da valorização da natureza como produtora, manejável por indivíduos que a conhecem e a mantêm viva, nas suas práticas cotidianas de trabalho.
} 
dependência do extrativismo de coleta em relação às frações do capital comercial e do capital portador de juros, consolidando uma lógica do aviamento sobre as relações de trabalho. Essa 'economia amazônica própria' (SANTOS, 1980) foi denominada Sistema de Aviamento.

Ainda que o extrativismo de coleta fosse lucrativo, seus pressupostos eram pouco compreendidos pelos agentes da metrópole que procuravam acompanhar os processos produtivos industriais, já compreendidos como hegemônicos na Europa do século XVIII, onde a terra era vista como mercadoria e cujo domínio distinguia a aristocracia rural e as elites urbanas. Além disso, a formação da sociedade e da metrópole industrial pressupunha a reestruturação do campo e exploração da natureza, assumida como matéria prima e fonte de recursos primários; o êxodo rural e a ampliação do exército industrial de reserva para o trabalho assalariado repetitivo e de baixa qualificação nas indústrias. Na virada do século XIX para o século XX, nos países que se industrializavam durante a segunda fase da revolução industrial, a grande aglomeração ainda permitia o aumento da renda média da população, o acesso às melhores condições de moradia, serviços e equipamentos públicos, e, em alguns contextos, a possibilidade de organização social e da reivindicação de direitos (HALL, 1995; MUMFORD, 1998). Os parâmetros de riqueza e bem-estar social permitidos por esse padrão de industrialização e urbanização seriam estabelecidos como referência de desenvolvimento econômico, inspirando promessas de que os países de inserção periférica poderiam alcançar as mesmas condições de produção e de vida por meio do planejamento econômico conduzido pelo Estado, contanto que fosse capaz de superar elementos estruturais e a dependência externa, ambos produto da formação econômica subdesenvolvida (FURTADO, 1974).

Essa perspectiva, associada ao desenvolvimento do capitalismo industrial, em sua segunda fase que se estabelece de meados do século XIX em diante, em nada se encaixava ao modo de vida nas várzeas amazônicas, caracterizados por ciclos periódicos de secas e cheias que fertilizam o solo, sustentando a vegetação nativa e também a roça, a criação de animais, a pesca e a coleta do camponês-caboclo, que retirava e retira da natureza viva o suporte material para sua sobrevivência (CANTO, 2007). O desinteresse pelas drogas do sertão e a extinção da Companhia de Comércio, entre o fim do século XVIII e a primeira metade do século XIX, deram uma trégua às populações campesinas, que desde então passaram a viver de forma autossuficiente, no seu isolamento, espacial e temporal (OLIVEIRA; SCHOR, 2008).

A consolidação do ciclo gomífero representou, acima de tudo, a conexão da formação amazônica às determinações do capitalismo industrial dos países 
europeus, o que obrigou à superação de limites impostos pelas características da força de trabalho regional (VENTURA NETO, 2020). Os nordestinos retirantes, fugidos das secas históricas que assolavam a região no mesmo período, paulatinamente se adaptaram às adversidades do sistema de aviamento, tornando-se suporte fundamental na coleta do látex (FURTADO, 2007). O sistema do barracão empório camuflava um sistema de escravidão sustentado por uma dívida impagável com o seringalista rural ou o aviador urbano, que transformou o nordestino em seringueiro que, ao permanecer na Amazônia, mesmo após o fim da fase gomífera, como ribeirinho ou pequeno agricultor, transforma definitivamente o espaço regional (BENCHIMOL, 2009).

As análises de longo prazo, do modo como as frações internas do capital comercial regional se articularam durante e após o ciclo gomífero, evidenciam um padrão de disputa pela hegemonia do bloco de poder regional, que se funda no controle dos lucros permitidos com o extrativismo de coleta e a superexploração do camponês caboclo. Nesse sentido, os agentes com poder econômico, o proprietário da casa aviadora e o pequeno capitalista local, que operavam a drenagem dos produtos da floresta visando obter lucros com a exportação para o mercado externo, fomentaram uma experiência urbana em Belém pautada em padrões de consumo e condições de vida importados das metrópoles industriais. Contudo, se em momentos de auge do ciclo extrativista a disputa entre os capitais locais reduzia-se às diferenças de margem de lucro, mas assegurava a importação de tecnologias e soluções de serviços, desenvolvidos a partir das reivindicações das classes trabalhadoras da cidade industrial europeia, em momentos de crise do ciclo extrativista, o custo da vida urbana tornava-se extremamente alto, o que criava as condições internas para que as reações das frações internas do capital industrial reivindicassem políticas de cunho desenvolvimentistas para valorizar a região.

No mundo rural, o camponês-caboclo continuava isolado, desinformado e desarticulado dessa realidade, facilmente estigmatizado como preguiçoso por não ser regido pelo tempo comercial, e visto como menos evoluído e inferior hierarquicamente aos olhos do agente moderno/colonial (CRUZ, 2008). Essa perspectiva positivista de que o progresso levaria ao desenvolvimento econômico, à modernização e um melhor posicionamento na divisão internacional do trabalho, constituiu-se em discurso oficial, fortalecido com a dissolução das formações socioespaciais coloniais, a integração do mercado e a expansão da acumulação comandada pelo capital em suas diversas frações (industrial, agropecuário, imobiliário etc.) (VENTURA NETO, 2017). Sob essa perspectiva, o caboclo camponês, peça chave do sistema de aviamento e da geração de riqueza na Amazônia, tornava-se um entrave para o desenvolvimento capitalista 
nos marcos do desenvolvimentismo, seu desaparecimento ou invisibilização se fazia necessário para que o instituto da propriedade privada da terra, o financiamento público e as relações de produção capitalista pudessem finalmente ser estabelecidos na região.

\section{ACONSTRUÇÃO DO DESENVOLVIMENTISMO NA AMAZÔNIA E SEUS REFLEXOS SOBRE O USO DA TERRA}

O termo teórico desenvolvimentismo é tradicionalmente usado para nomear tanto um fenômeno na esfera do pensamento, quanto um conjunto de políticas econômicas concatenadas que, conduzidas de forma deliberada por governos (nacionais e subnacionais), viabilizam o crescimento das forças produtivas e a superação dos problemas econômicos e sociais daquela sociedade, sob a liderança do setor industrial (FONSECA, 2015). No Brasil, o desenvolvimentismo deve ser entendido como a ideologia de transformação da sociedade brasileira que, após 1930, foi aplicada dentro de um projeto econômico que enxergava a industrialização integral do território como a via possível para a superação da pobreza e do subdesenvolvimento (BIELSCHOWSKY, 2000). Uma condição que definiu os rumos de integração do mercado nacional e das políticas estatais direcionadas ao desenvolvimento das forças produtivas nacionais, criando lastro para a consolidação de um quadro complexo de desigualdades regionais em função dos distintos graus de aprofundamento do parque industrial, disperso e desarticulado, entre os estados do país (CANO, 2002).

Por um lado, nas principais cidades da Amazônia, que detinham um parque industrial de baixa complexidade e condicionado pelas limitações da renda interna, a integração com o mercado nacional foi decisiva para o colapso de grande parte da indústria manufatureira que havia se consolidado a partir dos anos de 1930. Por outro lado, no extenso mundo rural regional, o desenvolvimentismo pressionava a transformação da floresta originária em "terra com mata", ou em outras palavras, a mercantilização da terra rural e sua apropriação como mercadoria capitalista (COSTA, 2010b).

O processo de homogeneização do território conduzido a partir da integração e das políticas desenvolvimentistas pode ser segmentado em duas fases. A primeira, de viés mais endógeno, correspondeu à fase de reorganização de instituições de financiamento criadas na Amazônia durante o esforço de guerra, quando a Superintendência do Plano de Valorização Econômica da Amazônia (SPVEA) foi consolidada como principal instituição de planejamento regional e o Banco de Crédito da Borracha foi convertido em Banco de Crédito 
da Amazônia (BCA) (FERNANDES, 2010). A segunda fase foi marcada pela centralização característica da ditadura militar, em que as instituições respondiam a planos nacionais de desenvolvimento, e que transformou a Superintendência de Desenvolvimento da Amazônia (SUDAM), sucessora da SPVEA, em principal instituição de planejamento da região, e o Banco da Amazônia (BASA), sucessor do BCA, em braço creditício dos fundos setoriais voltados para o desenvolvimento regional.

Esse conjunto articulado de experiências permitiu a rápida disseminação do discurso desenvolvimentista e da integração da região à economia nacional, com a consequente perda de hegemonia de frações do capital comercial regional que exerciam lugar de controle sobre as relações socioespaciais de produção ainda pautadas no aviamento, que, por sua vez, desarticulou as relações de dominação que atavam a elite de aviadores e exportadores (urbanos) ao espaço da várzea, e à força de trabalho do campesinato caboclo (rural) (VENTURA NETO, 2017). Assim, o que era sintetizado naquele espaço dentro do tradicional sistema rio-quintal-roça-mata (LOUREIRO, 2014) passou a ser substituído pela lógica desenvolvimentista da terra-mercadoria, rapidamente dilapidada nos seus recursos naturais e transformada em ativo fundamental para viabilizar políticas de ocupação econômica da Amazônia.

Isso porque, nos anos finais da SPVEA, o embrionário projeto de desenvolvimentismo-regionalista já estava liquidado e as formas de demarcação da propriedade fundiária sobrepujaram a base concreta e topológica de mensuração e utilização da floresta, difundida nas regiões de várzeas, e tornaramse hegemônicas. Em grande medida, esse processo teve como ponta de lança o traçado da rodovia Belém-Brasília, concluída em leito de barro no ano de 1958, que representou o triunfo do desenvolvimentismo e da integração da Amazônia ao mercado nacional, posicionando a ampliação da malha rodoviária nacional como modal prioritário para circulação de mercadorias e pessoas (CANO, 2002). Dentre as grandes metas de investimento em transporte rodoviário previstas pelo I Plano Quinquenal da SPVEA, a rodovia Belém-Brasília (BR-010) foi a única a ser concluída durante o tempo de existência da SPVEA ${ }^{2}$. Além de conectar fisicamente a Amazônia aos estados do Sudeste, a Belém-Brasília foi especialmente importante na transformação do mercado de terras na região Sul e Sudeste do Pará, dado o elevado interesse externo pelas terras próximas à rodovia em que grande parte ainda definidas como devolutas nos registros do governo

2 Para além da rodovia, parte significativa dos gastos da SPVEA foi direcionada para a estabilização do fornecimento de energia elétrica de Belém e Manaus, além do financiamento da primeira fábrica de cimento da região norte, em Capanema no nordeste paraense. 
paraense $^{3}$. O interesse externo passou a definir o sentido do mercado fundiário na região, antecipando o panorama futuro de predominância do latifúndio e conflitos pela posse da terra.

De fato, a concessão do uso (arrendamento) ou venda de títulos de terras devolutas era prática corriqueira no Executivo paraense desde meados dos anos 1940, e se constituía em uma das principais ferramentas do clientelismo estadual (SCHMINK; WOOD, 2012). Os dados da Tabela 1 mostram o avanço dessa prática nos anos iniciais de utilização da rodovia, de 1959 a 1963, quando a concessão de terras devolutas pelo Governo do Pará atingiu um total superior a cinco milhões de hectares, em 1.575 títulos de terras que possuíam em média 3.585 hectares cada.

Tabela 1 - Concessão de terras devolutas do estado do Pará, inclusive as de jurisdição do Departamento de Colonização do governo paraense

\begin{tabular}{|c|c|c|c|c|c|c|c|}
\hline \multirow[b]{2}{*}{ Períodos } & \multirow{2}{*}{$\begin{array}{l}\text { Núme- } \\
\text { ro de } \\
\text { títulos }\end{array}$} & \multirow{2}{*}{$\begin{array}{c}\text { Docu- } \\
\text { mentos } \\
\text { de colo- } \\
\text { nização } \\
\text { expedidos }\end{array}$} & \multirow{2}{*}{$\begin{array}{l}\text { Área } \\
\text { por } \\
\text { título } \\
\text { (ha) }\end{array}$} & \multirow{2}{*}{$\begin{array}{c}\text { Área por } \\
\text { docu- } \\
\text { mento de } \\
\text { coloniza- } \\
\text { ção (ha) }\end{array}$} & \multicolumn{2}{|c|}{$\begin{array}{c}\text { Total de área vendi- } \\
\text { da/arrendada }\end{array}$} & \multirow{2}{*}{$\begin{array}{c}\text { Total } \\
\text { de área } \\
\text { concedi- } \\
\text { da para } \\
\text { coloniza- } \\
\text { ção }\end{array}$} \\
\hline & & & & & Simples & $\begin{array}{l}\text { Acumu- } \\
\text { lado }\end{array}$ & \\
\hline 1928-1928 & 123 & & 315,2 & & 38769,6 & 38769,6 & \\
\hline 1929-1933 & 48 & & 1805,8 & & 86678,4 & 125448 & \\
\hline 1934-1938 & 47 & & 1351,9 & & 63539,3 & 188987,3 & \\
\hline 1939-1943 & 76 & & 1176,3 & & 89389,8 & 278377,1 & \\
\hline 1944-1948 & 42 & & 225,6 & & 9475,2 & 287852,3 & \\
\hline 1949-1953 & 136 & & 261,8 & & 35604,8 & 323457,1 & \\
\hline 1954-1958 & 368 & & 165,5 & & 60904 & 384361,1 & \\
\hline 1959-1963 & 1575 & 3753 & 3585 & 21,63 & 5646375 & 6030736,1 & 81171,9 \\
\hline 1964-1968 & 267 & 2325 & 3149 & 23,58 & 840771,1 & 6871507,2 & 54823,4 \\
\hline 1969-1973 & 33 & 2184 & 719 & 24,70 & 23725,8 & 6895233 & 53936,7 \\
\hline 1974-1976 & 29 & 6696 & 3149,1 & 32,53 & 91325 & 6986558 & 217805,4 \\
\hline Total & 2744 & 14958 & 15904,2 & 102,44 & & 28411286 & 407737,4 \\
\hline
\end{tabular}

Fonte: Dados do Instituto de Terras do Pará, sistematizados por Santos (1978) e Ventura Neto (2017, p. 168)

Os dados que apresentam a propriedades desses títulos na região sudeste do Pará apontam que a pressão sobre o governo estadual para o aforamento das terras devolutas parece ter partido de grandes comerciantes e usineiros da castanha-do-pará, particularmente os que possuíam usinas em Belém (BARROS,

\footnotetext{
Com a demarcação das terras devolutas no início do século XX, seguindo as diretrizes da Lei de Terras de 1850, o governo do Pará tornou-se um grande proprietário de terras devolutas no Estado e, entre 1920 e 1950, os governadores utilizavam a prerrogativa de arrendar terras devolutas como forma de atender às elites locais (SANTOS, 1978).
} 
1992). Isso ocorreu em virtude da possibilidade imediata de perda para agentes externos de áreas com castanhais nativos que ainda se encontravam em áreas devolutas nas proximidades da nova rodovia (EMMI, 1988).

A demarcação pelo governo estadual do chamado polígono dos castanhais foi o primeiro passo para a mercantilização da terra rural como mercadoria capitalista; a Figura 1 articula mapas em diferentes escalas para ilustrar como o polígono dos castanhais foi inserido na área dos grandes projetos federais (Rodovias, Projeto Grande Carajás), instrumentalizando o processo de homogeneização do território, na medida em que poligonais passaram a delimitar castanhais arrendados a particulares, que progressivamente foram privatizados e eliminaram as "estradas de coleta" que, até então, serviram de base concreta para a utilização e demarcação da floresta pela força de trabalho ribeirinha (EMMI, 2002).

Figura 1 - Esquemas de aproveitamento do território: do plano abstrato do desenvolvimentismo ao uso concreto do extrativismo. Esquerda: representação esquemática das ações que o governo militar planejou para a Amazônia. Direita: Representação da subdivisão da terra a partir da instituição do polígono dos castanhais e, em detalhe, das antigas "estradas de coleta" que definiam o potencial de aproveitamento das áreas utilizadas para o extrativismo de coleta nas várzeas e florestas
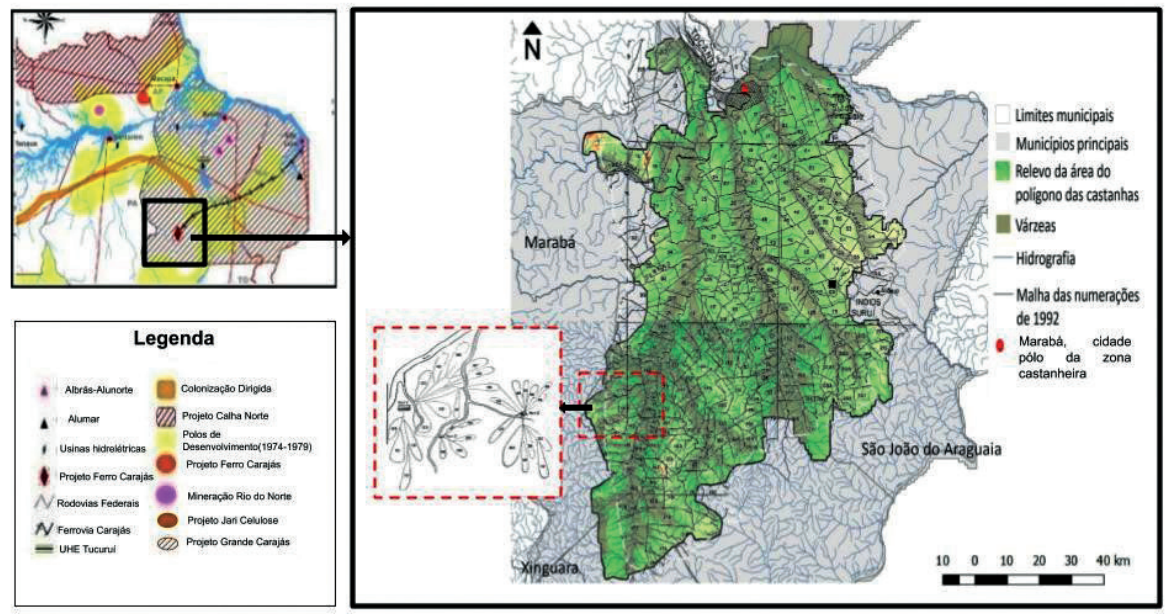

Elaboração: Cristina Cardoso e Brenda Santos (2020) a partir de dados cartográficos extraídos de The India Rubber World (PEARSON, 1902, p. 15), Barros (1992, p. 57), Emmi (2002), Rocha e Gonçalves (2017) e Miranda et al. (2005).

Antes do processo de integração, sob a ótica extrativista e do aviamento, o valor e a negociação das terras eram efetivamente baseado na quantidade de 
estradas (rotas de coleta) existentes em seus domínios. Essas evidências foram atestadas pelas análises de Weinstein (1993), dos inventários e testamentos de aviadores e seringalistas do período áureo da borracha, bem como por Santos (1980), que demonstrou como a produtividade dos seringais foi fator dependente da quantidade de estradas de coleta possíveis de serem percorridas pelo seringueiro durante um dia de trabalho. Destaque-se que o critério de dimensionamento das estradas relacionava-se à quantidade de árvores de coleta e não à distância a ser percorrida pelo trabalhador.

$\mathrm{Na}$ vida cotidiana do mundo rural amazônico essa condição organizava relações topológicas entre a força de trabalho ribeirinha e o território, que pressupunham não só a convivência entre o homem e a floresta preservada, mas principalmente a imprecisão de limites segundo os moldes capitalistas. Nesse sentido, o avanço na demarcação da floresta significava também a sua própria fetichização como mercadoria capitalista, camuflando tanto as relações de dominação ali presentes quanto às especificidades do território (VENTURA NETO, 2020). Pelo artifício das poligonais, a floresta se converteria em terras mensuradas não mais por estradas e sim por hectare, uma das mais antigas estratégias de acumulação primitiva em regiões de fronteira do capitalismo.

Após o golpe de 1964, as políticas desenvolvimentistas foram recondicionadas para subsidiar investimentos produtivos que favoreciam o protagonismo do centro dinâmico da economia nacional, na condução da forma e ritmo de acumulação, sobre a periferia do sistema (CANO, 2007). A articulação entre SUDAM e BASA, atendendo às diretrizes incluídas nos planos nacionais de desenvolvimento e nos respectivos Planos de Desenvolvimento da Amazônia, viabilizaram formas de investimentos que transformaram a Amazônia em fronteira interna de acumulação do capital nacional e internacional (BECKER, 2013). A SUDAM foi estruturada à semelhança da SUDENE, em sua segunda fase (CANO, 2002), para gerir os fundos constitucionais utilizados para garantir incentivos e concessões fiscais a empresas nacionais e estrangeiras interessadas em investir na Amazônia. Ao BASA, foi delegada a função de braço financeiro da SUDAM, como banco de desenvolvimento, de forma análoga às funções do Banco do Nordeste (BNB). Sua estratégia primordial era incentivar a industrialização como motor do desenvolvimento regional amazônico, moldada no pressuposto cepalino de substituição das importações (VENTURA NETO, 2017).

Cabe destacar que mesmo sendo a principal instituição de desenvolvimento regional da Amazônia, com o poder de supervisionar e fiscalizar os demais órgãos regionais, sua autonomia era fortemente condicionada pelo modelo instituído para aplicação dos fundos públicos do governo federal. Porque, durante boa 
parte do governo militar, a SUDAM não dispôs do controle direto dos recursos financeiros destinados à Amazônia, o que subordinou fortemente suas estratégias de desenvolvimento regional à utilização dos incentivos fiscais pelo setor privado, com prioridade dada aos projetos de agricultura e agropecuária, que já em 1967 concentrariam 73\% dos recursos disponíveis nessa rubrica (LIRA, 2005). Uma concentração que se ampliou até o início dos anos 1970, quando os recursos do FINAM passaram a financiar os programas de colonização e de expansão da malha rodoviária da região (CARVALHO, 1999). Nesse contexto, as políticas regionais passaram a ter um papel preponderante na reinvenção da periferia nacional para o capital sudestino (CANO, 2002), contando com uma vultuosa geração de riqueza permitida por processo de acumulação primitiva permanente, pelo avanço da mercantilização da terra rural na região e pela reprodução de relações não capitalistas que serviam para viabilizar as próprias estruturas capitalistas de produção necessárias para a abertura da fronteira (MARTINS, 2009).

No caso da SUDAM, o valor das terras de propriedade das empresas poderia ser contabilizado como recurso próprio e contrapartida dentro do projeto de financiamento apresentado ao órgão. Isso não só desobrigava o empresário a possuir uma significativa reserva financeira para captar o projeto, quanto possibilitava a especulação com o preço da terra rural na Amazônia. Durante todo o período de atuação da SUDAM, estima-se que o valor contábil das terras correspondia a $92 \%$ dos recursos próprios dos projetos, com uma frequência maior entre os projetos menores, nos quais os valores das terras chegavam a corresponder três vezes mais do que os recursos próprios, enquanto nos grandes projetos agropecuários esse valor equivaleria a pouco mais de $30 \%$ dos investimentos com recursos próprios (COSTA, 2012b).

A política de incentivos à agropecuária consolidou uma prática do reinvestimento dos recursos próprios, provenientes dos possíveis lucros do projeto, para ampliar o estoque de terras da empresa, o que moldou o embrionário mercado de terras rural de forma eminentemente especulativa e contribuiu para o aumento nos casos de grilagem nas regiões de influência das rodovias federais planejadas ou em execução na Amazônia. Na frente de expansão da Amazônia dos anos 1960 e 1970, a terra rural era o único ativo do empresário que não perdia valor com o tempo; o baixíssimo preço da terra rapidamente se valorizava com a derrubada da floresta ou com investimentos em infraestrutura realizados no seu entorno. Compôs-se um círculo vicioso de investimentos de viés especulativo em terra rural determinante para o aumento de conflitos agrários em algumas regiões do Pará. 
De posse das isenções fiscais, a demarcação efetiva da terra normalmente seria acompanhada da derrubada de mata nativa e da venda das madeiras nobres que possuíam algum interesse comercial (SCHIMINK; WOOD, 2012). Desse ponto em diante, em algumas regiões da Amazônia, inverteu-se a predominância do extrativismo de coleta, em privilégio do extrativismo de aniquilamento, especialmente madeireiro (COSTA, 2012b), que acabaria servindo como fonte importante de capitalização para o empresário da região.

Em outro extremo, a transformação da floresta em "terra com mata" dependeria de estratégias específicas de ressignificação das formas de dominação sobre a força de trabalho regional. A nova condição do campesinato-caboclo de posseiro das terras recém-demarcadas comprometia a sua reprodução a partir do extrativismo de coleta, obrigando-o a tentar uma nova vida como miserável urbano, ou a se submeter a práticas de superexploração nas fazendas agropecuárias como peão.

Apesar de incapazes de transformar a Amazônia em sua totalidade, as políticas desenvolvimentistas, implantadas com mais rigor e autoritarismo até os anos 1980, materializadas como políticas regionais de desenvolvimento, redefiniram o status da terra rural na região. Essa redefinição assumiu a biodiversidade da floresta como ativo circulante, como capital de giro de um empreendimento que contava com os hectares da propriedade como principal ativo fixo. A conversão da floresta em mercadoria capitalista trouxe em seu rastro a eliminação de formas tradicionais de geração da riqueza, nas quais a manutenção da biodiversidade ocorria articulada com práticas tradicionais do extrativismo de coleta, visando à consolidação de uma monocultura, muitas vezes de baixa produtividade, voltada prioritariamente para mercados externos à região.

\section{A PRESSÃO SOBRE A VÁRZEA INSERIDA EM CONTEXTO METROPOLITANO E URBANO: OS CASOS DE BELÉM E MOCAJUBA}

A despeito do aumento da pressão internacional pela preservação da Amazônia, colocada a partir da ECO 1992, o avanço do discurso neoliberal nas primeiras décadas do século XXI foi determinante para que outros espaços sub-regionais, distintos das regiões sul e sudeste do Pará - que foram as mais afetadas pelas políticas da SUDAM -, passassem a sofrer com movimento de 
especulação fundiária desenfreada e práticas de acumulação primitiva ${ }^{4}$, com frequente derrubada da mata e aterramento das várzeas.

Os casos das várzeas da metrópole Belém e da área urbana do município de Mocajuba, no Baixo Tocantins, ilustram bem esse processo. Em Belém, a tolerância histórica a usos rurais era comum até a metade do século XX, nas áreas alagáveis inseridas na área patrimonial da cidade (FISCHER et al., 2017). Apesar da conduta portuguesa de apropriação de sítios indígenas para a implantação de cidades e vilas, o colonizador instituiu a prática de extinção da várzea nas áreas planejadas da cidade, por aterro e canalização de rios. Mas, a despeito do alinhamento da lógica colonial à lógica capitalista de abstração do território para sua transformação em mercadoria, as áreas de baixadas (várzeas inseridas no atual centro metropolitano) foram ocupadas apenas após o avanço da reestruturação produtiva no território rural paraense. Até os anos 1950, a cidade canalizou e aterrou alguns rios, mas manteve quintais generosos e as baixadas desocupadas, e constituiu cinturões periféricos (ver áreas verdes próximas ao aeroporto, na Figura 2), que marcaram os ciclos de expansão da cidade e receberam usos institucionais. Este cenário começou a ser alterado partir da década de 2010, quando trechos de grandes áreas institucionais militares começaram a ser incorporadas pelo circuito imobiliário (LOPES, 2015), e as áreas verdes nos miolos das quadras - os quintais desvaneceram na área central da cidade (VENTURA NETO; MOURA, 2019).

Nos anos 2010, a mancha urbana conurbada alcançou os municípios de Ananindeua e Marituba, onde esse processo de supressão do verde vem sendo reproduzido, por conta das constituições institucionais mais frágeis e da subordinação mais clara das condições de uso e ocupação do território ao mercado (QUEIROZ, 2019). Apesar das características fisiográficas e do contexto socioambiental, a cidade de Belém e sua área metropolitana ainda estão longe de contar com uma política voltada para a preservação da sua sociobiodiversidade, a exemplo do que já existe há décadas no continente europeu (PARLAMENTO EUROPEU, 2009). Na RMB ocorre progressiva artificialização do solo (MIRANDA et al., 2019), desmatamento e expulsão de grupos sociais oriundos das várzeas da região (concentrados na região onde predominam os portos regionais, na Figura 2), que articulavam ocupações urbanas e rurais em sítios sujeitos a alagamento (as baixadas de Belém) ou em áreas da borda da mancha

4 Cardoso, Melo e Gomes $(2015,2016)$ quantificam a expansão urbana das cidades de Santarém, Altamira, São Félix do Xingu, Marabá, Parauapebas e Canaã dos Carajás, ocorrida a partir de 1970, identificando processos de polinucleação que mesclam tipologias rurais e urbanas, caracterizando uma urbanização extensiva (MONTE-MOR, 1994), que afeta de forma muito diferenciada os grupos sociais. 
urbana (de caráter periurbano), como ocorreu com a comunidade que cultivava alimentos na horta do bairro da Terra Firme ${ }^{5}$.

Sob a ótica da gestão municipal e estadual, a tendência de espraiamento e adensamento da mancha urbana tem sido compensada pela criação de áreas de preservação estaduais e municipais de caráter estritamente ambiental (ver Figura 2), com maiores investimentos feitos nas áreas com forte apelo paisagístico, priorizando o turismo e o lazer, em detrimento do planejamento de um sistema de áreas verdes que seja capaz de apoiar o extrativismo urbano, fomentar a manutenção de corredores verdes com a preservação de quintais, de potencializar a absorção das chuvas, pela manutenção de solo não urbanizado em meio à mancha urbana, e em última instância, contribuir para a redução de emissões de $\mathrm{CO}_{2}$, conforme estabelecido pelas metas internacionais, mas principalmente para a formulação de novos paradigmas de desenvolvimento, mais adequados à realidade da região. Além de reconhecer que a preservação e o apoio ao manejo de matas periurbanas, somados à valorização de saberes e tecnologias tradicionais, são formas de apoiar a economia popular e a soberania alimentar.

Figura 2 - Região Metropolitana de Belém. Destaque para mosaico de UC, logística e fluxos

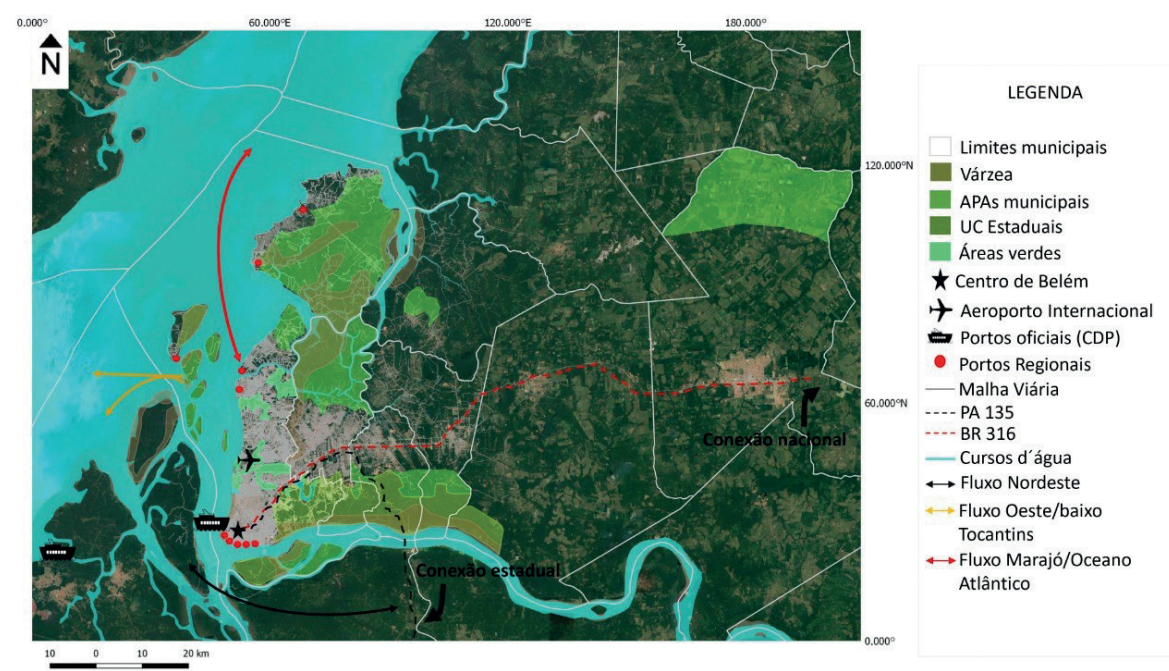

Fonte dos dados: IBGE (2019), DNIT (2011), IDESP (2012) e IDEFLOR-BIO (2019). Elaboração: Cristina Cardoso e Brenda Santos (2020)

Em decorrência da formação de uma mancha urbana contínua, a várzea de Belém foi transformada em área de risco, sujeita às inundações e colapso do

5 Ver Cardoso, Vicente e Oliveira $(2018,2019)$. 
sistema viário por ocasião das fortes chuvas, com tendência de intensificação a cada ano (SOUZA et al., 2016). Não há conexão entre o debate do risco e adaptação ao contexto de mudanças climáticas com as práticas socioeconômicas e a realidade tecnológica e ambiental amazônicas; rios continuam sendo mortos, áreas desmatadas e impermeabilizadas, biodiversidade perdida, enquanto cresce a desigualdade social (MORAIS; KRAUSE; LIMA NETO, 2016). Não há convergência na discussão sobre aspectos econômicos e ambientais, justiça ambiental e a pobreza da população.

Mocajuba ${ }^{6}$ apresenta outra face desse processo, trata-se de um município que conta com áreas de terra firme e de várzea e onde a cidade era fortemente articulada a esses dois contextos. Até 15 anos atrás era comum que todo habitante da cidade também soubesse manejar a várzea e tivesse acesso à sua biodiversidade como parte do seu sustento. O cultivo de pimenta enriqueceu as elites locais, no período em que a UHE Tucuruí impactava a vida na várzea, cuja população não era alcançada por políticas públicas e dependia do extrativismo, na pequena produção familiar, e da solidariedade distribuída em assentamentos agroextrativistas e quilombolas reconhecidos (ver inserção de localidades na zona de várzea, na Figura 3) (OLIVEIRA, 2020). A estagnação do comércio e da cidade, após a barragem do rio, manteve a complementaridade entre cidade e várzea, mas a falta de modernização tecnológica no trabalho caboclo desestimula os jovens e motiva o êxodo para a cidade, sem que existam alternativas para absorção de sua mão de obra, uma vez que a cidade não foi preparada para absorver os migrantes rurais e suas práticas, que dependeriam da preservação dos rios, igarapés, praias e matas periurbanas. Não há ocupação para esses jovens, nem para os migrantes que chegaram após a construção de um presídio na cidade, ao mesmo tempo em que ocorreram modernizações (asfaltamento) que suprimiram a vegetação de grande porte das ruas; a população local reporta aumento da violência local e a feira reflete o declínio da produção local de alimentos, com elevado índice de importação dos produtos comercializados ${ }^{7}$.

Cidade com 164 anos, localizada em sítio de terra firme, às margens do rio Tocantins, a jusante da barragem da UHE Tucuruí, em frente ao arquipélago de várzea povoado por comunidades caboclas e quilombolas. Antigo porto e feira da rota fluvial entre Marabá e Belém, sofreu declínio comercial e impacto ambiental após a construção da barragem. O fluxo fluvial foi redirecionado para estradas regionais, que conectam Belém a Tucuruí, de menor fluxo do que as rodovias federais.

7 Informações obtidas em trabalho de campo realizado entre 13 e 14 de janeiro de 2019, por equipe de seis pesquisadores (docente e estudantes) responsáveis pela realização de grupos focais na escola da comunidade de Mangabeira e na paróquia da comunidade de Santana, ambas localizadas nas ilhas, e em levantamentos e entrevistas com moradores realizadas na sede municipal. 
Figura 3 - Município de Mocajuba, com destaque para várzea, sede, vilas e fluxos

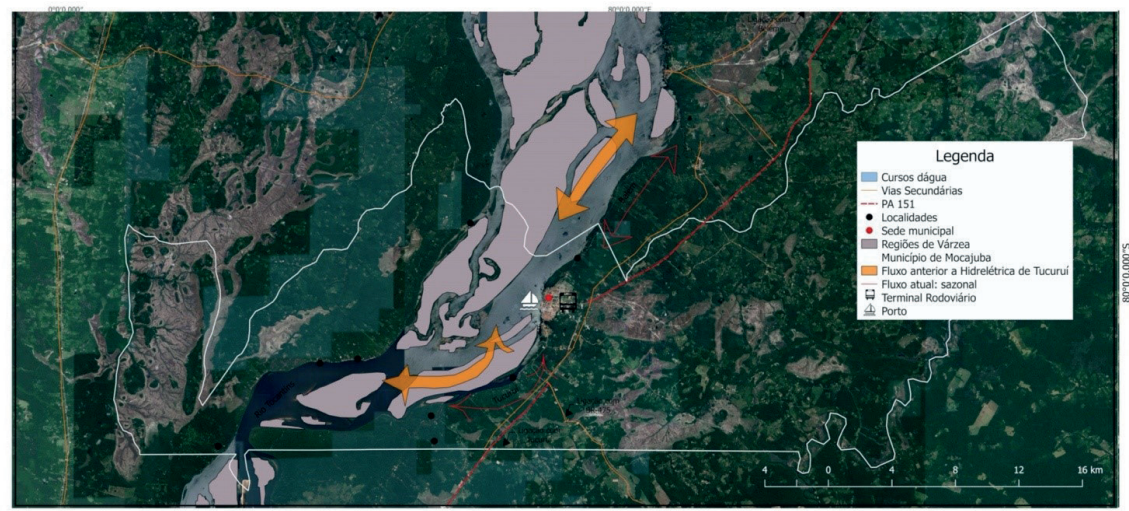

Fonte dos dados: IBGE (2019), DNIT (2011) e IDESP (2012).

Elaboração: Cristina Cardoso e Brenda Santos (2020)

A alternativa econômica em expansão tem sido o cultivo de açaí. Com o sucesso comercial dessa "nova" commodity, constituiu-se forte pressão para que a racionalidade empresarial se estenda sobre a várzea. A migração da população rural para a capital do estado e para outras cidades, desencadeada pela reestruturação produtiva do universo rural da Amazônia, aumentou a demanda do fruto como alimento da gastronomia local, enquanto sua difusão no país e no exterior como bioenergético tornou-o um produto de elevado valor comercial na Europa, particularmente na França, onde uma dose pode ser servida por mais de cem euros (CORTEZZI, 2019). O estudo de Tagore, Canto e Sobrinho (2018) para a várzea do município de Abaetetuba, mais próximo da Região Metropolitana de Belém, ilustra como a demanda pelo fruto do açaí conteve o desmatamento da várzea praticado até os anos de $1980^{8}$ para a exploração de palmito, mas introduziu novas condições de manejo em açaizais das áreas de várzea. Segundo esses autores, as novas práticas resultam em riscos ambientais porque promovem: (a) mudança da configuração da paisagem pelo monocultivo do açaí; (b) erosão e assoreamento dos rios; e (c) eliminação de espécies que protegem as margens das áreas de várzea, colocando o ecossistema de várzea sob risco.

$\mathrm{Na}$ cidade de Mocajuba, a ruptura do vínculo com a várzea resulta na reprodução de processos típicos das grandes cidades. A praia é o espaço público que mantém a conexão entre cidade e natureza, no restante da cidade ocorre supressão de vegetação e de quintais, contaminação de cursos d'água,

8 Nos anos de 1980, o Pará foi a principal unidade da federação na extração e produção de palmito em conserva, responsável por $95 \%$ da produção nacional, graças à ocorrência endêmica do açaí em suas várzeas (MOURÃO, 2010). 
impermeabilização do solo, como parte de uma rejeição simbólica do vínculo histórico com a biodiversidade, que é complementada por uma releitura da natureza como amenidade paisagística disponível na frente da cidade (a praia), ou preferencialmente para quem pode pagar pelo acesso ou se tornar proprietário dos sítios com esses atributos localizados nas margens do rio Tocantins. A biodiversidade foi associada ao trabalho duro e à baixa renda, ainda que a vida na várzea seja mais farta e seja unânime a avaliação de perda de qualidade de vida por parte dos antigos varzeiros que mudaram para a cidade (pesquisa de campo, 2019).

\section{CONSIDERAÇÕES FINAIS}

A reestruturação produtiva imposta ao campo, e o decorrente êxodo rural, provocaram uma lenta transformação na região amazônica, que afeta campo e cidade e requer políticas e práticas de justiça ambiental, para além da mera redução de desmatamento ou o reflorestamento. Observa-se que as unidades de conservação são reservas de valor, mais que estratégias de redução do desmatamento no Brasil ou de apoio ao modo de vida local. Enquanto os países industrializados procuram reduzir emissões com menor quantidade de carros das estradas, o caso de Belém revela a implantação do modo de vida suburbano já obsoleto nos países do Norte Global, viabilizado pelo desmatamento para conversão de uso em áreas periurbanas. A falta de pesquisa tecnológica e de leitura da realidade ideologiza o modo de vida do camponês caboclo como atrasado, antes de avaliar a compatibilidade desse modo de vida com as demandas do novo contexto ambiental do planeta.

A visão da terra como insumo à produção da agroindústria ou do setor imobiliário e a desarticulação entre as dimensões urbana e ambiental na gestão pública foram ampliadas e disseminadas nos últimos 50 anos. Apesar de mais de $80 \%$ da população da região viver em cidades e vilas, ainda existe grande dependência do acesso a bens primários (biodiversidade, água e solo não contaminados) na produção tradicional - que efetivamente sustenta a gastronomia exótica da região. Um novo olhar para o processo em curso em Mocajuba poderia resultar em uma solução regional e na necessária preservação de biodiversidade (IBPES, 2019). A riqueza do bioma amazônico depende dos agentes sociais que sabem manejá-la, que ao serem excluídos do campo e da cidade, precisam de soluções socioambientais - que interconectam campo e cidade por meio da criação de assentamentos que possam mantê-los em terras públicas designadas para esse fim, muitas vezes disseminando estratégias de aproveitamento do sítio 
de várzea que conflitam com o interesse neoliberal de acentuar o valor da terra como mercadoria.

Estes assentamentos ainda não são reconhecidos como uma possível estratégia de proteção de biodiversidade, e tendem a ser desmantelados pelas determinações na nova lei de Regularização Fundiária (BRASIL, 2017) que prevê a sua extinção e a incorporação das terras ocupadas por eles ao mercado privado de terras. Enquanto isso, entre 2019 e 2020, a natureza ofereceu várias demonstrações de reação (incêndios, inundações e pandemia) à limitada perspectiva humana do avanço da urbanização na Amazônia e no planeta.

\section{REFERÊNCIAS}

BARROS, M. V. M. A zona castanheira do médio Tocantins e vale do Itacaiúnas: reorganização do espaço sob os efeitos das políticas públicas para a Amazônia. 1992. Monografia (Graduação em Geografia) - Departamento de Geografia, Universidade Federal do Pará, Marabá, 1992.

BECKER, B. A urbe amazônida: a floresta e a cidade. São Paulo: Garamond, 2013.

BENCHIMOL, S. Amazônia: formação social e cultura. Manaus: Editora Valer, 2009.

BIELSCHOWSKY, R. Pensamento econômico brasileiro: o ciclo ideológico do desenvolvimentismo. Rio de Janeiro: Contraponto, 2000.

BRASIL. Lei N $\mathbf{N}^{\mathbf{0}} \mathbf{1 3 . 4 6 5}$, de 11 de julho de 2017. Dispõe sobre a regularização fundiária rural e urbana, sobre a liquidação de créditos concedidos aos assentados da reforma agrária e sobre a regularização fundiária no âmbito da Amazônia Legal. Brasília, DF: Presidência da República, [2017]. Disponível em: http://www. planalto.gov.br/ccivil_03/_Ato2015-2018/2017/Lei/L13465.htm. Acesso em: 20 maio 2020.

CANO, W. Ensaios sobre a formação econômica regional do Brasil. Campinas: Editora Unicamp, 2002.

CANO, W. Desequilíbrios regionais e concentração industrial no Brasil 1930-1970. São Paulo: Editora UNESP, 2007.

CANTO, O. Várzea e varzeiros da Amazônia. Belém: MPEG, 2007.

CARDOSO, A.; VICENTE, L.; OLIVEIRA, R. Os padrões espaciais e morfológicos de comunidades na Amazônia: subsídios para uma nova forma 
de pensar a natureza. In: ENCONTRO DA ASSOCIAÇÃO NACIONAL DE PESQUISA E PÓS-GRADUAÇÃO EM ARQUITETURA E URBANISMO ANAIS, 5., 2018, Salvador. Anais [...]. Salvador: UFBA, 2018. p. 1-17.

CARDOSO, A.; VICENTE, L.; OLIVEIRA, R. Os invisíveis portadores de futuro. Cadernos de Pós-Graduação em Arquitetura e Urbanismo, v. 19, n. 1, p. 23-37, jan./jun. 2019. Disponível em: http://editorarevistas.mackenzie.br/ index.php/cpgau/article/view/11965. Acesso em: 29 jul. 2019.

CARVALHO, D. O ciclo da economia brasileira e a Amazônia na dinâmica regional centro-periferia. Papers do NAEA, Belém, n. 120, p. 1-42, maio 1999.

CORTEZZI, F. M. Géographie de la circulation commerciale d'un fruit amazonien: le processus de diffusion mondial de l'açaí, du Brésil au reste du monde (le cas de Paris - France). 2019. Thesis (Doctorate em Géographie) Université de Sorbonne, Paris, 2019.

COSTA, F. A. Lugar e significado da gestão pombalina na economia do GrãoPará. Nova Economia, Belo Horizonte, v. 20, n. 1, p. 167-206, 2010 a.

COSTA, F. A. Mercado e produção de terras na Amazônia: avaliação referida a trajetórias tecnológicas. Bol. Mus. Para. Emílio Goeldi. Ciênc. hum., Belém, v. 5, n. 1, p. 25-39, abr. 2010b. Disponível em: http://www.scielo.br/scielo. php?script $=$ sci_arttext\&pid $=$ S1981-81222010000100004\&lng $=$ pt\&nrm $=$ iso. Acesso em: 26 maio 2020.

COSTA, F. A. Formação rural extrativista na Amazônia: os desafios do desenvolvimento capitalista (1720-1970). Belém: NAEA, 2012a.

COSTA, F. A. Formação agropecuária da Amazônia: os desafios do desenvolvimento sustentável. Belém: NAEA, 2012b.

CRUZ, V. O rio como espaço de referência identitária: reflexões sobre a identidade ribeirinha na Amazônia. In: TRINDADE JÚNIOR, S-C. C.; TAVARES, M. G. (org.). Cidades ribeirinhas na Amazônia: mudanças e permanências. Belém: EDUFPA, 2008. p. 49-69.

DNIT. Rodovias do Brasil. DNIT, Brasília, DF, 2011 [cartografia digital, formato shapefile]. Disponível em: http://www.dnit.gov.br/mapas-multimodais/ shapefiles. Acesso em: 23 maio 2018.

EMMI, M. F. A oligarquia do Tocantins e o domínio dos castanhais. Belém: NAEA/UFPA, 1988. 
EMMI, M. F. Os castanhais do Tocantins e a indústria extrativa no Pará até a década de 60. Papers do NAEA, Belém, n. 166, p. 1-25, out. 2002.

FERNANDES, D. A. A questão regional e a formação do discurso desenvolvimentista na Amazônia. 2010. Tese(Doutorado em Desenvolvimento Socioambiental) - Programa de Pós-Graduação em Desenvolvimento Sustentável do Trópico Úmido, Núcleo de Altos Estudos Amazônicos, Universidade Federal do Pará, Belém, 2010.

FISCHER, L. et al. (org.). Análise dos aforamentos municipais concedidos entre 1815 e 1930. São Paulo: Acquerelo, 2017. (Relatório de Pesquisa).

FONSECA, P. Desenvolvimentismo: a construção do conceito. Rio de Janeiro: IPEA, 2015.

FURTADO, C. O mito do desenvolvimento econômico. Rio de Janeiro: Paz e Terra, 1974.

FURTADO, C. A formação econômica do Brasil. São Paulo: Companhia das Letras, 2007.

HALL, P. Cidades do amanhã. São Paulo: Perspectiva, 1995.

HECHT, S. B.; PEZZOLI, K.; SAATCHI, S. Chapter 10. Trees have already been invented: carbon in woodlands. Collabra, [S. 1.], v. 2, n. 1, art. 24, p. 1-34, Dec. 2016. Disponível em: https://www.collabra.org/articles/10.1525/ collabra.69/. Acesso em: 19 out. 2019. Disponível em: https://www.collabra. org/articles/10.1525/collabra.69/. Acesso em: 19 out. 2019.

IBGE. Malha Municipal. IBGE, Rio de Janeiro, 2019. Disponível em: https://www.ibge.gov.br/geociencias/organizacao-do-territorio/estruturaterritorial/15774-malhas.html?=\&t=downloads. Acesso em: 06 abr. 2020.

IPBES. The global assessment report on biodiversity and ecosystem services. IPBES, Bonn, 29 jul. 2019. Disponível em: https://www.ipbes.net/globalassessment-report-biodiversity-ecosystem-services. Acesso em: 29 jul. 2019.

IDERFLOR-BIO. Unidades de Conservação. IDERFLOR-BIO, Belém, 2019. Disponível em: https://ideflorbio.pa.gov.br/unidades-de-conservacao/. Acesso em: 06 abr. 2020.

IDESP. Malha viária da Região Metropolitana de Belém (RMB). IDESP, Belém, 2012. 1 shapefile. 1 CD ROM. 
IPCC. Managing the risks of extreme events and disasters to advance climate change adaptation (SREX). New York: Cambrigde University Press, 2012.

LIRA, S. R. Morte e ressurreição da SUDAM: uma análise da decadência e extinção do padrão de planejamento regional na Amazônia. Belém: NAEA/ UFPA, 2005.

LOPES, R. Transformações recentes no uso e dominialidade das áreas das forças armadas no cinturão institucional de Belém. 2015. Dissertação (Mestrado em Arquitetura e Urbanismo) - Programa de Pós-Graduação em Arquitetura e Urbanismo, Universidade Federal do Pará, Belém, 2015.

LOUREIRO, V. R. Amazônia, estado, homem, natureza. Belém: Cultural Brasil, 2014.

MARTINS, J. S. Fronteira: a degradação do outro nos confins do humano. São Paulo: Contexto, 2009.

MIRANDA, T.; CARDOSO, A.C.;ESCADA, M.I.; GONÇALVES, G. Expansão urbana de Belém e seus arranjos morfológicos: desafio às políticas urbanas e ambientais. In: PORTUGUESE NETWORK URBAN MORPHOLOGY, 8. 2019. Anais [...]. Maringá: UEM, 2019. p. 482-502.

MIRANDA, E. E. (coord.). Brasil em Relevo. Campinas: Embrapa, 2005. Disponível em: http:/ /www.relevobr.cnpm.embrapa.br. Acesso em: 26 maio 2020. MORAIS, P.; KRAUSE, C.; LIMA NETO, V. Caracterização e tipologia de assentamentos precários: estudos de caso brasileiros. Brasília, DF: IPEA, 2016.

MOURÃO, L. História e natureza: do açaí ao palmito. Revista Territórios e Fronteiras, Campo Grande, v. 3, n. 2, p. 74-96, jul./dez. 2010.

MUMFORD, L. A cidade na história. São Paulo: Martins Fontes, 2004.

OLIVEIRA, K. D. Entre a várzea e a terra firme, estudo de espaços de assentamentos tradicionais urbano rurais na região do Baixo Tocantins. 2020. Dissertação (Mestrado em Arquitetura e Urbanismo) - Programa de Pós-Graduação em Arquitetura e Urbanismo, Universidade Federal do Pará, Belém, 2020.

OLIVEIRA, J. A.; SCHOR, T. Das cidades na natureza à natureza das cidades. In: TRINDADE JÚNIOR, S-C. C.; TAVARES, M. G. (org.). Cidades ribeirinhas na Amazônia: mudanças e permanências. Belém: EDUFPA, 2008. p. 15-26. 


\section{PARLAMENTO EUROPEU. Directiva 2009/147/CE do Parlamento} Europeu e do Conselho, de 30 de novembro de 2009. Relativa à conservação das aves selvagens. Bruxelas: Parlamento Europeu, 30 nov. 2009. Disponível em: https:/ / eur-lex.europa.eu/LexUriServ/LexUriServ.do?uri=OJ:L:2010:020:000: 0025:PT:PDF. Acesso em: 29 jul 2019.

QUEIROZ, V. O ambiente periférico metropolitano: o caso de MaritubaPA. 2019. Dissertação (Mestrado em Arquitetura e Urbanismo) - Programa de Pós-Graduação em Arquitetura e Urbanismo, Universidade Federal do Pará, Belém, 2019.

ROCHA, G. M.; GONÇALVES, S. F. S. Considerações sobre a federalização e a gestão compartilhada do território da Amazônia brasileira. Confins, Paris, n. 30, 2017. Disponível em: https://journals.openedition.org/confins/11665. Acesso em: 22 maio 2020.

SANTOS, R. A economia do Estado do Pará. Relatório de pesquisa No. 10. Belém: Governo do Estado do Pará: IDESP, 1978. (Relatório de Pesquisa).

SANTOS, R. História econômica da Amazônia: 1800 - 1920. São Paulo: T.A. Queiroz, 1980.

SCHMINK, M.; WOOD, C. Conflitos sociais e a formação da Amazônia. Belém: EDUFPA, 2012.

SOUZA, E. B.; CARMO, A. M. C.; MOARES, B. C.; NACIF, A.; FERREIRA, D. B. S.; ROCHA, E. J. P.; SOUZA, P. J. O. P. Sazonalidade da precipitação sobre a Amazônia legal brasileira: clima atual e projeções futuras usando o modelo regcm4. Revista Brasileira de Climatologia, Curitiba, v. 18, p. 293-306, 2016.

STOLL, E. Rivalités riveraines: territoires, stratégies familiales, et sorcellerie en Amazonie brésilienne. 2014. Thesis (Doctorate em Anthropologie) - École Pratique des Hautes Études, Paris; Programa de Pós-Graduação em Ciências Ambientais, Universidade Federal do Pará, Belém, 2014.

TAGORE, M.; CANTO, O.; SOBRINHO, M. V. Políticas públicas e riscos ambientais em áreas de várzea na Amazônia: o caso do PRONAF para produção do açaí. Desenvolvimento e Meio Ambiente, Paraná, v. 45, p. 194-214, abr. 2018.

PEARSON, H. C. (org.). India Rubber World. New York, n. 1, v. 27, Apr. 1902. THERE is a river above us. [S. l.: s. n.], 15 mar. 2011. 1 vídeo (21 min). Publicado pelo canal TEDx Talks. Disponível em: https://www.youtube.com/ watch?v=01jYiXbpnoE. Acesso em: 29 jul. 2019. 
VENTURA NETO, R. A (trans)formação socioespacial da Amazônia: floresta, Rentismo e Periferia. 2017. 297 f. Tese (Doutorado em Desenvolvimento Econômico) - Instituto de Economia, Universidade Estadual de Campinas, Campinas, 2017.

VENTURA NETO, R. Notas sobre a formação socioespacial da Amazônia. Nova Economia, Belo Horizonte, 2020. (No prelo).

VENTURA NETO, R.; MOURA, B. M. Jardins de granito: impactos da verticalização sobre as áreas permeáveis da Primeira Légua Patrimonial de Belém, Pará. Revista Projetar: projeto e percepção do ambiente construído, Natal, v. 4, p. 38-53, 2019.

VICENTINI, Y. Cidade e história na Amazônia. Curitiba: EDUFPR, 2004.

WEINSTEIN, B. A borracha na Amazônia: expansão e decadência (18501920). São Paulo: Hucitec/Edusp, 1993. 